\title{
Food Hygiene/Microbiological Safety in the Typical Household Kitchen: Some Basic 'Must Knows' for the General Public
}

\author{
Charles Odilichukwu R. Okpala ${ }^{1 *}$ (D) and Ifeoma M. Ezeonu ${ }^{2}$ \\ ${ }^{1}$ Independent Academic Research Practice Consultant, c/o Aguiyi Ironsi Street, Off Finbars Road, Umuahia, Abia \\ State, Nigeria. ${ }^{2}$ Department of Microbiology, University of Nigeria, Nsukka, Enugu State, Nigeria.
}

\begin{abstract}
The primary objective of food hygiene is to eliminate or reduce the risk of exposure to foodborne illness. Biological, chemical and/ or physical agents contaminating food may cause foodborne illness, but by far the most common causes are biological agents, with microorganisms constituting a major proportion. Although consumers express hygiene/microbiological safety concerns about public dining places/kitchens, a significant proportion of foodborne outbreaks actually occur in homes. The general public needs to get equipped with some fundamental knowledge about food hygiene/microbiological safety (FHMS) in typical household kitchens and some of these are presented in this concise review. Microorganisms may gain access to and contaminate food through various routes including the hands of individual(s) preparing the food, cooking utensils, water for cooking, among others. Given the ubiquity of microorganisms and various routes of contamination of food, one can safely say that it is extremely difficult, if not impossible, to achieve total purity in terms of food contamination. Therefore, food hygiene/ microbiological safety should target, not necessarily to totally eliminate microorganisms from food, but to prevent any continued proliferation and/or production of toxins in food. Understanding the food hygiene/microbiological safety concept(s) definitions can help to enhance the knowledge base of kitchen user(s) with respect to principles of foodborne diseases and food safety practices. In this concise review also, some common modes of microbial contamination in household kitchen as well as food safety practices will be discussed, to help educate the general public as well as reduce the incidence of foodborne illnesses within household kitchen contexts.
\end{abstract}

Keywords: Food hygiene, Food safety, Microbiology, Domestic/household kitchen, Consumer protection.

\footnotetext{
*Correspondence: charlesokpala@gmail.com

(Received: 20 April 2019; accepted: 18 June 2019)

Citation: Charles Odilichukwu R. Okpala, and Ifeoma M. Ezeonu, Food Hygiene/Microbiological Safety in the Typical Household Kitchen: Some Basic 'Must Knows' for the General Public, J Pure Appl Microbiol., 2019; 13(2): 697-713. doi: 10.22207/JPAM.13.2.06

(C) The Author(s) 2019. Open Access. This article is distributed under the terms of the Creative Commons Attribution 4.0 International License which permits unrestricted use, sharing, distribution, and reproduction in any medium, provided you give appropriate credit to the original author(s) and the source, provide a link to the Creative Commons license, and indicate if changes were made.
} 


\section{INTRODUCTION}

The domestic/household kitchen has always been associated with food preparation, and largely extends to both consumption and storage. A typical kitchen comprises of various gadgets and appliances, ranging from small items such as spoons, knives and cutting boards to large appliances such as microwave ovens, dishwashers and cookers. And potentially, how complete a kitchen typically is would largely depend on the household's economic status. Regardless of how equipped a typical household kitchen may appear to be, it is most likely that the level of food safety awareness, knowledge and practice of a given kitchen user might directly associate with the hygiene situation of a given kitchen. Besides, there are some basic food hygiene/ microbiological safety (FHMS) concept definitions that all kitchen users should possess. By having so, they (kitchen users) will become equipped with some useful knowledge base to help build-up their capacity to actualize, realize and sustain a healthy kitchen environment. Keeping the components of household kitchen at top-notch hygiene condition is very essential because such practice would help consolidate kitchen users' efforts in implementing the microbiological safety at all food preparation/ storage stages. And by achieving such feat, the microbiological safety of a food dished out from a (typical) household kitchen can be considered as consumer protected and safe. Clearly, consumers are very useful candidates within their kitchen environment contexts given their capacity to prevent the incidence as well as spread of foodborne diseases/illnesses.

The primary purpose of food hygiene is to eliminate or reduce the risk of (human) exposure to foodborne illness. This, and with respect to household kitchen environment, can be achieved when kitchen users have acquired some thorough knowledge and understanding of kitchen components and its associated microbial hygiene/safety, coupled with some basic principles of food hygiene /microbiological safety. Therefore, activities within the kitchen should be such that adhere to good food safety attitudes and practices. For example, Hazard Analysis and Critical Control Points (HACCP) recognized by Food and Agricultural Organization (FAO) of the United Nations, European Commission, Australian and
New Zealand Food Authority and World Health Organization (WHO) are already becoming increasingly popular in developing countries as a tool that ensures food safety ${ }^{1}$. Although many consumers have often expressed concern about restaurant kitchens and public dining places, there is evidence of statistics that show a significant number of all foodborne outbreaks actually occur in homes. According to the most current Centre for Disease Control (CDC) surveillance report, in 2016 alone, there were 76 outbreaks (10\%) and 895 reported cases of illness (7\%) in the United States, which were attributed to food prepared in private homes ${ }^{2}$. On the other hand, the European Food Safety Authority (EFSA) indicated the most reported setting for foodborne disease outbreaks were registered as 'household/domestic kitchen' (in 2013) ${ }^{3}$.

Whilst home kitchens are well known to serve, not only as storage place(s), but also as multipurpose areas, consumers have a critical key role to play in the prevention of foodborne disease incidence. Besides, the different sources from which microorganisms can be transferred to food are well known. These include: the hands, body fluids or clothing worn by individual preparing the food; unclean kitchen utensils, unclean water for cooking, house pets, etc. Any living or non-living thing found in the kitchen, which may harbor microorganisms that can be transferred to food at any stage of preparation, may serve as a source of contamination. Indeed, contamination of food by microorganisms can occur in any of several stages of food preparation, from raw food and ingredients, the cooking or preparation process up to handling and storage of the cooked food.

- Contamination of raw food and ingredients: Many raw foods including vegetables, tubers, roots, which are grown in the soil, are naturally contaminated by microorganisms in the soil and even after washing, cells of such microorganisms remain on the raw food. Fruits on trees contain deposits of microbial cells and spores from the air. Raw foods from animal sources, such as meats and milk are contaminated with microorganisms from the animals' skin and intestines during slaughter and milking, respectively.

- Contamination during cooking: Contamination during cooking occurs when 
microorganisms introduced into the food as described above or introduced from unclean water used for cooking, unclean cooking utensils, hands, sneeze, cough or other body secretions, are not eliminated during the cooking process. Most bacteria associated with foodborne illness will be killed if exposed to temperatures between 60 and $80^{\circ} \mathrm{C}$; mold fungi will require higher temperatures, while both bacterial and fungal spores will require temperatures near boiling or higher. If the food containing these microbial elements is not cooked such that every part of the food attains the appropriate temperature, the contaminants may remain in the food. Moreover, vegetables usually are not heated to high temperature. Therefore, the contaminating microorganisms must be eliminated by mechanisms other than heat.

- $\quad$ Contamination of cooked food: The most common mechanism of contamination of cooked food is the improper handling of the ready-to-eat food, which allows microorganisms from raw food or unclean objects to touch the ready-to-eat food. For example, while frying chicken, the kitchen user may use the same spatula to go from the raw chicken to the already fried chicken, transferring microbes to the ready-to-eat chicken in the process.

In the light of the abovementioned information (and others not mentioned) that may be found in the typical household kitchen, there is need to examine its food hygiene/microbiological safety (FHMS) aspects, in the view to supplement existing information. Therefore, the specific objective of this contribution is to perform a concise review about food hygiene and microbiological safety in the typical household kitchen. Here, we break down this important food-health household topic into fundamental and simpler phases/points, with the aim to make contents of the evolving sub-topics bit less technical, with increasing clarity and understanding for the average home kitchen user as well as wider scientific community. This concise review is constructed as follows: some basic food hygiene /microbiological safety (FHMS) concept definitions applicable to domestic/ household kitchen; snapshots of some key foodborne pathogens and corresponding diseases/ illnesses; kitchen components and associated microbial hygiene/safety; food hygiene and microbiological safety in a typical kitchen; as well as human activities/participation in food hygiene microbiological safety.

Some Basic Food Hygiene/Microbiological Safety (FHMS) Concept Definitions Applicable to Domestic/Household Kitchen

To achieve high level of food hygiene/ microbiological safety in the typical domestic/ household kitchen should, in our opinion, start with acquisition of both knowledge and understanding of some fundamental concept definitions and associated endeavor(s). Such knowledge and understanding would help shed more light about the principles underscoring food hygiene microbiological safety contexts and feasibly any (associated/relevant) applications. Herein, some basic food hygiene/microbiological safety concepts associated with kitchen, according to the discretion of authors are succinctly highlighted below: cross-contamination, susceptibility, food hygiene/safety/poisoning, foodborne disease/ illnesses, safe handling practices, disinfecting/ disinfectant, cleaning/sanitizing, microbial growth/proliferation, reservoir of foodborne illness, dissemination of foodborne disease, resident microbial flora, microbial biofilms, signs/ symptoms, nausea, bacteremia, septicemia, diarrhea, hemorrhage and pathogenicity/ virulence. These concept definitions below are succinctly outlined:

\section{Cross-contamination}

According to United States Department of Agriculture (USDA), cross-contamination is the transfer of harmful bacteria to food from other foods, cutting boards, utensils, etc., if they are not handled properly. This is especially true when handling raw meat, poultry, and seafood, so keep these foods and their juices away from already cooked or ready-to-eat foods and fresh produce ${ }^{4}$.

\section{Susceptibility with respect to food safety}

This is the capability of an individual to get sick from contaminated food. For example, vulnerable people such as the very aged/elderly or ill/sick are more susceptible to infection caused by foodborne pathogens that would result in serious consequences compared to healthy adults ${ }^{5}$.

\section{Food hygiene}

According to World Health Organization (WHO), food hygiene refers to the conditions and measures necessary to ensure the safety of food from production to consumption. Food 
can become contaminated at any point during slaughtering or harvesting, processing, storage, distribution, transportation and preparation. Lack of adequate food hygiene can lead to foodborne diseases and death of the consumer ${ }^{6}$.

Food safety

According to Australian Institute of Food Safety, food safety refers to the handling, preparing and storing food in a way to best reduce the risk of individuals becoming sick from foodborne illnesses. Food safety is a global concern that covers a variety of different areas of everyday life? Food poisoning

According to Better Health Channel of Victoria State Government of Australia, food poisoning occurs when sufficient numbers of particular types of bacteria, or their toxins, are present in the food we consume. It is these bacteria that are termed 'pathogens's.

\section{Foodborne disease}

According to WHO, foodborne diseases are understood to encompass a wide spectrum of illnesses, which result from ingestion of foodstuffs contaminated with either chemicals or microorganisms. Importantly, the contamination of food may occur at any stage, from food production to consumption, and can emerge from environmental contamination, including pollution of water, soil or air?.

\section{Foodborne illnesses}

According to National Institute of Diabetes and Digestive and Kidney Diseases (NIDDK), foodborne illnesses are understood as infections or irritations of the gastrointestinal (GI) tract caused by food or beverages that contain harmful bacteria, parasites, viruses, or chemicals. The GI tract is a series of hollow organs joined in a long, twisting tube from the mouth to the anus. Common symptoms of foodborne illnesses include vomiting, diarrhea, abdominal pain, fever, and chills ${ }^{10}$.

\section{Safe handling practice in food safety}

This concept is well to known and largely describes guidelines/processes by which potential hazards/risks in food products are minimized, with the aim to enhance both productivity and quality. Disinfectant

According to the Center for Disease Control and Prevention (CDC), the term 'disinfectant' is ascribed to chemical agent(s) used on inanimate objects (i.e., nonliving) (e.g., floors, walls, sinks) to destroy virtually all recognized pathogenic microorganisms, but not necessarily all microbial forms (e.g., bacterial endospores). The EPA has grouped disinfectants based on whether the product label claims/indicates "limited," "general" or "hospital" disinfectant ${ }^{11}$.

\section{Disinfection}

According to the Center for Disease Control and Prevention (CDC), the term 'disinfection' refers to the destruction of pathogenic and other kinds of microorganisms by physical or chemical means. Disinfection is less lethal than sterilization, because it destroys most recognized pathogenic microorganisms, but not necessarily all microbial forms, such as bacterial spores. Disinfection does not ensure the margin of safety associated with sterilization processes ${ }^{11}$.

\section{Cleaning}

According to ServSafe ${ }^{\circledR}$, cleaning removes food and other types of soil from a surface such as a countertop or plate ${ }^{12}$.

\section{Sanitizing}

According to ServSafe ${ }^{\circledR}$, sanitizing reduces the number of pathogens on that clean(ed) surface to safe levels ${ }^{12}$.

\section{Microbial growth}

In microbiology, the concept 'microbial growth' is defined as a process of increase in the number of cells of an organism. For example, bacteria grow and divide by binary fission, a rapid and relatively simple process. Fundamentally, requirements for growth are physical (temperature, $\mathrm{pH}$, osmotic pressure) and chemical (from carbon, nitrogen, sulphur, phosphorus, up to oxygen $)^{13}$.

\section{Microbial proliferation}

This simply refers to continuous increase in microbial growth/numbers, which to a large extent depends on organism(s) type present as well as initial concentration of microorganisms ${ }^{14}$.

\section{Reservoir of foodborne illness}

According to Victoria State of Government of Australia's hub for health services, whilst soil, dust, cereals serve as reservoirs for food and water-borne illness, and fish, birds, reptiles, and wild and domestic mammals serve as reservoirs for bacteria and parasites, humans serve as the reservoir for viruses ${ }^{15}$. 


\section{Dissemination of foodborne disease/illness}

This well-known term widely considers the ability of a vector to distribute a microbial pathogen between one location and another location.

\section{Resident microbial flora}

According to WHO Guidelines on Hand Hygiene in Healthcare, the resident flora (resident microbiota) are understood to consist of microorganisms residing under the superficial cells of the stratum corneum and can also be found on the surface of the skin ${ }^{16}$.

\section{Microbial biofilms}

According to Davey and $\mathrm{O}^{\prime}$ toole ${ }^{17}$, biofilms refer to complex communities of microorganisms attached to surfaces or associated with interfaces. Such microbial communities are often composed of multiple species that interact with each other and their environment. The determination of biofilm architecture particularly the spatial arrangement of micro-colonies (clusters of cells) relative to one another have profound implications for the function of these complex communities.

Signs and symptoms

These (signs and symptoms) are abnormalities indicative of potential ill-health/ medical conditions. Whereas a symptom is subjective, that is, apparent only to the patient (for example, back pain and or fatigue), a sign is any objective evidence of an emergent disease condition, detected/observed by others (for example, a skin rash or lump $)^{18}$.

Nausea

This is a stomach discomfort resulting in sensation of want to vomit. It can be an originator to vomiting the contents of the stomach, and such condition has many causes and can often be prevented $^{19}$.

\section{Bacteremia}

This is an infection caused by bacteria that enters the bloodstream. It may also be referred to either as septicemia, sepsis, septic shock, blood poisoning and/or bacteria in the blood ${ }^{20}$.

\section{Septicemia}

Sepsis and septicemia are medical terms that refer to infections and human body response to such infections. Whilst the two words are not interchangeable (as it appears to be commonly so), sepsis is an extreme inflammatory response to infection, whereas septicemia is presence of bacteria in bloodstream that brings about sepsis, hence 'blood poisoning'21.

\section{Diarrhea}

A common health complaint characterized by abnormally loose/watery stool, largely caused either by bacteria, virus and/or parasites, which brings about infection in gastrointestinal tract. Examples of bacteria that would cause diarrhea include Salmonella spp., Campylobacter spp., Shigella spp. and Shiga toxin-producing Escherichia coli22.

\section{Hemorrhage}

It can refer either to blood loss inside (internal bleeding) or outside (external bleeding) the body, and can occur in almost any area of the body ${ }^{23}$.

\section{Pathogenicity}

This term refers to the ability of an organism to cause disease (i.e., harm the host). This ability represents a genetic aspect of pathogen together with overt damage done to the host as property of host-pathogen interactions ${ }^{24}$.

\section{Virulence}

This is a term often used interchangeably with pathogenicity. It refers to the degree of pathology caused by a given organism. The extent of virulence actually correlates with pathogen's ability to multiply within the host and may be affected by other factors, i.e., conditional ${ }^{24}$.

For a re-emphasis, the reason that we provide these concept definitions is to present readers with necessary background knowledge so as to understand the relevant food hygiene microbiological safety contents as well as contexts, whenever or wherever there are mentioned. This will place readers to be in a better position particularly those who are non-microbiology experts to adequately follow subsequent sections reasonably better, starting with some key foodborne pathogens and its corresponding diseases/illnesses.

\section{Snapshots of Some Key Foodborne Pathogens and} Corresponding Diseases/Illnesses

Having dealt with some food hygiene/ microbiology safety concept definitions, we will in this section provide snapshots of some key foodborne pathogens, particularly such bacteria as Salmonella spp., Campylobacter spp., Shiga toxin-producing Escherichia coli, Listeria spp. and Yersinia spp. and their corresponding diseases/ 
illnesses. To elaborate on these, the emphasis will be given to reservoir animals associated with these pathogens, food vehicles, mode of transmission and how disease in human eventually manifests via signs/symptoms. How such disease are treated will neither be highlighted nor discussed in this section (and current work) because authors deem it not within the remit of the specific objective of this concise review. We aim here to emphasize on foodborne pathogens and corresponding diseases/ illnesses potentially foreseeable in the typical household kitchen context so kitchen users to be aware that such foodborne pathogens do exist and can find its way into the kitchen particularly if hygiene standards get compromised to very low levels. And as such, all should be carried out in such a way to ensure high hygiene standards are maintained so as to prevent any disease incidence. 1) Salmonella spp. bacteria (with Salmonella typhimurium involved as principal species) have poultry, bovine, ovine, porcine and fish/seafood as reservoir animals. Hence, food vehicles can include poultry meat products, and eggs, undercooked meat or ground beef, as well as dairy products. The mode of transmission is ingestion of food or contaminated water, consumption of food of infected animal products. The disease in humans is largely localized gastroenteritis with such principal signs/ symptoms as nausea, vomiting, diarrhea, bacteremia, and up to septicemia ${ }^{25}$. Factors determining the virulence of Salmonella genus bacteria that allows for its infection and survival involves mechanisms of adherence to host's cells, invasion and replication inside host's cells, polysaccharide coating, and up to the production of toxins ${ }^{26}$.

2) Campylobacter spp. bacteria (with Campylobacter coli and C. jejuni as involved principal species) have poultry, cattle, pigs and piglets as reservoir animals. Thus, food vehicles can include poultry products, unpasteurized milk and water. The mode of transmission includes ingestion of contaminated food or water as well as consumption of food infected animals. The disease in human is Campylobacteriosis with such principal signs/symptoms as acute diarrhea, abdominal pain, fever, intestinal bloody diarrhea, esophageal diseases, functional gastrointestinal disorders, celiac disease, and up to colon cancer ${ }^{25}$. The attribute of Campylobacter genus bacteria that allows for its infection and survival involves mechanisms of mobility, drug resistance, adherence to host's epithelial cells, invasion of host's cells and production of toxins ${ }^{26}$.

3) Listeria spp. bacteria (with Listeria monocytogenes as involved principal species) have cattle, sheep, goats and poultry as reservoir animals. Thus, food vehicles can include crustaceans, mollusks, shellfish, cheese, beef, pork, vegetables and milk products. The mode of infection involves ingestion of contaminated food or water, direct content with infected animals or consumption of food from infected animals and person-to-person contact. The disease in human is Listeriosis with such principal signs/symptoms as invasive illness like meningitis, bacteremia, endocarditis, and up to non-invasive illness like febrile gastroenteritis ${ }^{25}$. In addition, factors that determine the pathogenicity of L. monocytogenes that substantiates its virulence involve adhesive protein, listeriolysin $\mathrm{O}$, secretion systems, phospholipases C (PICA and $\mathrm{PlcB})$, superficial proteins $A$ cta $A$, and the OrfX protein ${ }^{26}$.

4) Yersinia spp. bacteria (with Yersinia enterocolitica as involved principal species) have cattle, sheep and pig as reservoir animals. Thus food vehicles can include raw or undercooked pork, but also fresh and pasteurized milk, infected seafood as well as (drinking) water. The mode of infection involves ingestion of contaminated food or water, direct contact with infected animals, infected tissues and person-to-person contact. The disease in human is yersinosis with such principal signs/symptoms as severe gastritis and enteritis, fever, 
stomachache, diarrhea (often bloody) with complications like erythema, myocarditis, and less often sepsis and endocarditis ${ }^{26}$. Besides, factors/ mechanisms that facilitates the infection of $Y$. enterocolitica involves adhesion and invasion of host's cells, secretion system type III mobility, lipopolysaccharides, thermo-stable enterotoxins, production of urease, and up to avoidance of host's immunological response ${ }^{26}$.

5) Shiga toxin-producing Escherichia coli bacteria (with Senogroup 0151 as most common but 026, 045, 0103, 0111, 0121 and 0145 as involved principal species) has cattle, sheep, goats and a lower proportion of pigs, cats and (some) other ruminants. Hence, food vehicles can include undercooked ground meat, raw milk, raw vegetables, fruits, water, cheese and curd. The mode of transmission involves ingestion of contaminated food or water, direct contact with infected animals or consumption of food from infected animals and person-to-person contact. The disease in human is severe hemorrhagic colitis with such principal signs/symptoms as hemorrhagic diarrhea, acute abdominal cramping, vomiting, and up to hemolytic uremic syndrome (HUS) $)^{25}$.
One may ask why we have selected these abovementioned specific foodborne pathogens. We selected these because they have been enlisted as important foodborne pathogens of animal origin. Besides, food contamination brings about enormous socio-economic strain on societies. Year-in year-out, world population and across continents are affected by foodborne pathogens. Not only are chances of contamination and spread of foodborne pathogens on the rise, these pathogens enter the food chain anytime between farm and fork ${ }^{27}$. With the abovementioned information in mind, subsequent sections will deal with kitchen components and its associated microbial hygiene/safety, food hygiene/ microbiological safety in the typical kitchen, and human activities and participation in food hygiene/ microbiological safety.

\section{Kitchen Components and Its Associated Microbial Hygiene/Safety}

A well-furnished domestic kitchen will have components such as refrigerator/ freezer, kitchen utensils, cabinet/cupboard, sink/basin top, table/work top, cooker, oven as well as dishwasher. The usage of these kitchen components would vary from home to home, largely dependent on such factors as family size, level of automation, income level, consciousness and effort to achieve optimum hygiene, as well as the knowledge and understanding of kitchen hygiene. A hypothetical scenario of

Table 1. Hypothetical scenario of susceptibility to microbial contamination, frequency of usage and daily cleaning routine of various kitchen components

\begin{tabular}{|c|c|c|c|}
\hline $\begin{array}{l}\text { Kitchen } \\
\text { components }\end{array}$ & $\begin{array}{c}\text { Susceptibility to } \\
\text { microbial } \\
\text { contamination }\end{array}$ & $\begin{array}{l}\text { Frequency } \\
\text { of usage }\end{array}$ & $\begin{array}{l}\text { Daily routine } \\
\text { cleaning }\end{array}$ \\
\hline Floor & High & High & More frequent \\
\hline Kitchen utensils & High & High & More frequent \\
\hline $\begin{array}{l}\text { Utensil drainer } \\
\text { and tray }\end{array}$ & High & High & More frequent \\
\hline $\begin{array}{l}\text { Kitchen cabinets/ } \\
\text { cupboard }\end{array}$ & Low & Medium & Less frequent \\
\hline Table/work top & High & High & More frequent \\
\hline Cooker & High & High & More frequent \\
\hline Oven & High & Medium & Less frequent \\
\hline Dishwasher & High & High & More frequent \\
\hline Kitchen sink/basin & High & High & More frequent \\
\hline Fridge/Freezer & High & High & More frequent \\
\hline
\end{tabular}


susceptibility of microbial contamination, frequency of usage and daily cleaning routine of abovementioned kitchen components, is presented in Table 1 . The ratings provided in this table are hypothetical, presenting an ideal scenario wherein any given kitchen owner would possess a optimal knowledge and understanding of (food) hygiene and microbiological safety, and wherein the individual presumes high susceptibility of microbial contamination, all put together would then be resulting in an increase in the frequency of daily cleaning routine.

Essentially, cross-contamination of foodborne pathogens in household kitchen are among the key contributors to global foodborne illnesses ${ }^{28}$. Besides, cross-contamination by bacteria can take place in many sites in the kitchen. In line with this, cooking utensils such as knife, food processing surfaces as well as equipment/facilities used to clean the surfaces such as dishcloth, all engaged in the process of food preparation may get contaminated by any pathogen that may be present ${ }^{29}$. Also, materials that retain fewer microorganisms after cleaning would be the hygienic choice and would present a minor cross-contamination risk. For example, chopping board on a work/table top can be prone to cross-contamination particularly from juices of raw meat and poultry remaining on the surface, which result in a range of microorganisms spreading onto other foods subsequently prepared on the surface. It is possible that tear/wear can potentially affect the hygiene status of surfaces ${ }^{30}$.

When used utensils are washed in the kitchen, it is recommended that afterwards (used utensils) be kept in a (thermoset) plastic collection pack already equipped with a drain tray-like base, to allow for draining-off of water to achieve initial drying. And this (specific) tray-like base receiving the drained (out) water essentially requires regular cleaning to ensure it keeps dry. It is also recommended that (fluff-free) dishcloths be used to equally ensure that these utensils, including pots etc., are very dry before packing them away in a closed utensil drawer/shelf. And because such closed utensil drawer/shelf is most likely to be of wood types, it should be checked routinely, to make sure it stays clean, dry and odour-free. That being said, there is need for regular cleaning and drying of surfaces for such kitchen components as utensils, table/work top, cooker, oven, dishwasher, fridge and freezer. And the use of commercially available washing-up liquids can help play a useful role in sanitizing these surfaces.

Routinely and within the stipulated time periods, refrigerators should be thoroughly cleaned so as to help sustain top-notch hygiene standards and prevent the accumulation of bad odour. And depending on frequency of usage, freezers on the other hand should be thoroughly cleaned (now and then) although the cleaning frequency in this context would be much less compared with those of refrigerators. To keep components of household kitchen at top-notch hygiene conditions even before to consider the safety of food items becomes of great necessity especially when the primary focus is to control, mitigate and prevent either disease and or infection initiation/spread. To maintain top-notch hygiene for all kitchen components requires consistency, diligence, perseverance and avoidance of procrastination. For example, washing-off used plates (immediately/shortly) after use, wiping clean the microwave (immediately/shortly) after use, drying-up kitchen utensils immediately after washing prior to keeping them in their respective spaces, should be more of a habit and routine.

\section{Food Hygiene/Microbiological Safety (FHMS) in a Typical Kitchen}

The possible sources of food contamination are well known to be numerous considering the ubiquitous nature of microorganisms. Consequently, it is common for these microorganisms to gain access to food. However, gaining access to food is one thing and growing in food is another. As mentioned previously, the fundamental target of food safety practice is to prevent either the proliferation of microorganisms and/or production of their toxins in food. Principally, the factors that affect microbial growth in foods leading to spoilage have been largely classified in terms of intrinsic, extrinsic and biotic aspects. Specifically, whilst intrinsic factors (inherent in food) involve biological structures, $\mathrm{pH}$, moisture, oxidation-reduction potential, antimicrobial constituents, and nutrient content, extrinsic factors (storage environment), affecting both food and associated microorganisms, involve relative humidity, atmosphere and temperature. Biotic factors, on the other hand, 
involve synergism, growth rate and metabiosis ${ }^{31}$. On the other hand, it is important to note that, to be aware of food-related risks would not necessarily suffice to either incite and or motivate individuals to apply good hygiene practices. Most probably, a change in how society of the day would perceive hygiene practices may well bring about (some) increases in microbiological hazards of home-prepared food(s) ${ }^{32}$.

Besides, both quality and safety of food products are considered to depend highly on (storage) temperature even when considering the perspective of preparation, up to consumption stages. Either above or below freezing points, cold storage appears to be the most common existing food preservation method. Besides, the misinterpretation of food storage instruction(s) would create some avenue for a given foodborne pathogen to arise and its corresponding disease/ illness risks to set $\mathrm{in}^{32}$. Therefore, for microbial growth to take place, there must be at least one viable cell even if the food (item) contains nutrients that would be sufficient to support microbial growth. This makes the fundamental aim of hygiene/microbiological safety in a kitchen very crucial, which is, to control these (abovementioned) factors, with the primary objective of reducing the number as well as presence of (pathogenic) microorganisms in food, which at the end would also be reducing the incidence/spread of foodborne illnesses.

The importance and main hazards of foodborne diseases should not be underestimated. In the USA, the cases of foodborne disease are estimated to be of greatest numbers due to known pathogens such as Norovirus, Salmonella spp., Clostridium perfringens, Campylobacter spp., and Staphylococcus aureus, whereas greatest numbers of deaths were caused by Salmonella, Toxoplasma gondii, Listeria monocytogenes, Norovirus and Campylobacter spp. ${ }^{5}$. Basically, foodborne illnesses caused by microorganisms are generally classified into two types: food infection and food intoxication. For emphasis, a food-borne illness is classified as food infection if the illness results from the consumption of live microorganisms, in food, which may grow in the body of the consumer and cause symptoms. On the other hand, it becomes (an) intoxication when the illness results from consumption of toxins produced in the food by contaminant microorganisms. Regardless, these illnesses may be avoided by knowledge of some basic facts about food safety. Factors that favor microbial growth in food have already been mentioned. Therefore, microbiological safety practices are such that counter these favorable factors to make the food unfavorable for growth of microorganisms and their activities. A few common examples are described below:

- When dishes and pots are washed in the kitchen, it is recommended that these utensils be left to dry before packing away. However, it is a common mistake in many homes for, especially lower income homes with small kitchens, to simply pack away dishes and pots after washing, without drying. There is a microbiological safety issue in this practice. Most microorganisms require moisture to grow; the more moisture there is, the more organisms can grow. If only 100 bacterial cells are deposited in a pot containing a little moisture, these 100 cells will multiply to almost 5000 cells in only six hours, whereas 1000 cells of bacteria deposited on a very dry surface would probably remain 1000 cells in the same six hours. Thus, a simple kitchen mistake such as not drying pots before storage could constitute a serious microbiological hazard in the kitchen.

- It is commonplace to prepare food much earlier before it is to be consumed, but this is also a microbiological risk in the kitchen. Storage of foods at room temperature should be avoided as much as possible. Many organisms can multiply rapidly at room temperature and just as in the example described above, a few bacterial cells deposited in food, particularly already cooked food, can rapidly multiply to great numbers in just a few hours, becoming sources of food infection or intoxication. However, storage of the food in the refrigerator can prevent the multiplication of these cells if the organisms are not psychrophilic (cold-loving). If food has been left at room temperature for a few hours, such food should be reheated before consumption.

Achieving high level microbiological safety within the kitchen context is not too difficult, but studies have showed that there is insufficient knowledge and practice of proper kitchen hygiene among home kitchen users, thus leading to an increased prevalence of food-handling mistakes 
in home kitchens ${ }^{33}$. Moreover, factors that favor the outbreak of foodborne diseases can include cross-contamination, poor hygiene state of food handlers, contamination of processed foods, storage of food at ambient temperature, avoiding preparation of food in advance and improper/ inadequate thawing of frozen foods ${ }^{31}$. Improper domestic food handling and unhygienic practices would be considered as vital in the extant sporadic cases of foodborne illnesses. In United Kingdom, Europe, Australia, New Zealand, United States and Canada, for example, there is evidence that up to $87 \%$ of foodborne disease outbreak would originate from food prepared or consumed at home ${ }^{28}$.

Nevertheless, the definition of food safety will not change from its key aim/objective and would continue to be associated with the conditions and practices that protect the quality of food, which helps to prevent the onset of contamination as well as subsequent incidence/ spread of foodborne disease/illness ${ }^{34}$. A healthy kitchen is therefore very essential in assuring high levels of food safety standards. For instance, avoiding germs is achievable by the four Cs of food safety, namely: cross-contamination, cleaning, cooking and chilling. Preventing crosscontamination ranges from washing hands before and immediately after handling raw food (e.g., meat, eggs) or after going to the toilet, disinfecting all surfaces immediately after food spillage, up to keeping pets away from food preparation/ eating areas ${ }^{35}$. Therefore, scenarios where the food preparation (activity) in the household kitchen could be deduced to bring about such cross contamination and this can take place at any of its components/sites. For example, such food products as beef, lamb, pork and seafood have been considered as key sources of bacteria contamination. L. monocytogenes is well known foodborne pathogen, established within the European Union, for example Portugal, to prevail in food products like milk, meat, fish, flour and fresh cheese. Not only that the bacteria are able to adhere onto these food items/stuffs, there are equally able to serve as a potential source of contamination, which may eventually lead to disease transmission ${ }^{29}$. Particularly, the persistence of microorganisms, presence and density of pathogens and potential spread of microbial contaminants from contaminated food have been documented in scientific literature. Previously reported microbial surveys of risk of infection spread in the home considered the kitchen as highest given the significant variety of bacterial contaminants, including fecal coliforms, Escherichia coli, Campylobacter spp., and Salmonella spp., even after the food had been prepared $^{36}$.

If hand hygiene applied within the kitchen context is to become effective, there is need to ensure that various areas of hand hygiene are covered considering the fact that the infectious dose' of (many common) foodborne pathogens are always very small. Some key aspects include detergent-based cleaning, chemical disinfectants, drying of surfaces (decontamination), and household water treatment. Thus, hand hygiene is very essential for the reason that the hand itself is among important source of cross-contamination. This situation can arise by contact and transfer of bacteria, fungi and viruses between hand and food surfaces, which would generally result in increased risk of exposure to foodborne infection. Moreover, hygiene procedures that break the chain of infection transmission are equally very crucial $^{37}$. Apart from hand, there are reservoir/ disseminations such as cloths, sponges, and other cleaning utensils, which if used correctly can aid detachment of particles from surfaces to remove significant proportion of soil and microbes present. There is also laundry concerns, where infection/ transmission risks associated with the kitchen cloths are likely to increase, for example, in the situation that a family member is with diarrhea or vomiting or skin or wound infection. Another reservoir of microorganisms in the kitchen is the sink, given the presence of moisture that provides ideal substrate to support growth of resident microbial population. Disinfection of sink therefore is recommended when there is an infected person, or person particularly vulnerable to infection. Routine cleaning and disinfection of sink is considered as appropriate means to prevent build-up of microbial biofilms at these sites ${ }^{37}$.

Many studies have considered kitchen components, small example like, sponges as a vital diffuser of pathogens that can cross-contaminate food, which inevitably serves as reservoir of food pathogens such as E. coli, Staphylococcus aureus 
and Salmonella spp. to thrive. And if transferred onto surfaces that are in contact with food (in the kitchen), these microorganisms have the capacity to remain viable for either hours and or days after contamination ${ }^{38}$. Bacteria transfer onto other foods/surfaces easily occurs via hands/ hand contact surface like cutting boards, knives and bowls. Good percentage of Salmonella spp. and Campylobacter spp. can spread to cutting boards during the preparation of naturally contaminated chicken. Salmonella spp. can transfer to tap handles in the same way. E. coli can transfer to contaminated cutting boards to lettuce even after overnight storage of cutting board. Most often and or always, dirty hands more or less do touch tap handles before hand washing. Essentially, hygienic cleaning of hand and food contact places help to reduce risk of cross contamination ${ }^{3}$. Meanwhile, hand washing during and after food preparation remains among control measures that help to reduce the occurrence of microbiological hazards especially within a given household ${ }^{32}$. In addition, the activity of cleaning ranges from decontaminating (used) kitchen items at the appropriate time to remove germs, up to encouraging the use of disposable cloths/ towels. Whilst cooking meat thoroughly kills microorganisms that can result in stomach upset, chilling foods to freezing temperature slows down microbial growth ${ }^{35}$.

For some time now, microbial concerns about both kitchen floor and wall have been with much debate. Besides, a (very) clean floor and wall would always demonstrate as well as reflect not only the nice appearance and welcoming household kitchen but also a (perceived) top-notch hygiene/microbiological safety level. Although it would not always be plausible for consumers (visitors, as in this instance) to have access and view a household kitchen so as to determine how clean the kitchen that have produced a given food dish is. In the situation where they have access to it, upon seeing a clean floor and wall (and presumably a very neat and well organized household kitchen), they (visitors) would certainly feel (a lot more) relaxed to consume the food dish brought before them. Hence, it would be worthwhile if future studies would pursue to fully establish how food hygiene versus cleaned kitchen environment would influence consumer feelings about food dish preparation, its consumption and even storage. Nonetheless, routine disinfection of floors has still met much opposition for the reason that it would do little to reduce cross infection risk where such exist. However, hygienic cleaning using disinfectant products continue to remain advisable in specific situations of increased risk, more specifically involving the presence of either an infected person, and or those vulnerable to infection. When spills of vomit, blood etc., have affected (kitchen) floor and walls, disinfection in addition to cleaning remain advisable ${ }^{37}$.

With all above said in this section of this review, the primary aim of safe food hygiene practices still remain to remove unwanted contaminants as it can poison food, which could result in negative impact on community health ${ }^{39}$. Even at low doses, microbes can still bring about infection, for the reason that pathogens can survive starting from hours for up to weeks, and can do so on several household surfaces ${ }^{40}$. Risk of human infection therefore remains an essential determinant to foodborne pathogen considering the latter's ability to persist or survive in the (food) produce ${ }^{41}$ even in the typical domestic/household kitchen. Implementing safe hygienic practices would therefore help in eliminating the risk of either infection and/or transmission of foodborne pathogens. Unquestionably, safety measures by consumers as final step in food preparation process are crucial in preventing foodborne illnesses and consumers' safe food handling in kitchen becomes 'the final line of defense' ${ }^{36}$.

\section{Human Activities/Participation in Food Hygiene/} Microbiological Safety (FHMS)

Some FHMS concept definitions applicable to household kitchen, snapshots of some key foodborne pathogens and corresponding diseases, kitchen components and its associated microbial hygiene/safety and food hygiene microbiological safety in kitchen have so far been discussed in this review. The next to identify with is how human carries out the activities of food hygiene / microbiological safety in the kitchen, followed by how it can be sustained. Firstly, for food as raw material to become edible and fit for purpose, there must be proper handling and preparation, which should come from the working efforts of food safety competent/qualified person(s). Secondly, how competent and/or qualified the 
person(s) (is/are) should remain very relative, which considers the (food hygiene/safety) training experience/expertise (already) acquired either through formal and/or informal means. Thirdly, what should be considered as more important is the person(s) to efficiently adhere to and function with the correct food hygiene/microbiological safety (FHMS) concepts/principles within the kitchen environment across the food raw material, preparation and consumption/storage stages.

To better understand the potential competences of a kitchen user as mentioned earlier, a reflection of two hypothetical scenarios would be useful. We consider two (promising) individuals ' $A$ ' and ' $B$ ': Individual ' $A$ ' from about 6-7 years of age had been extensively groomed in kitchen activities that spanned for about 15 years (informal), may well possess some equivalent food hygiene/microbiology safety knowledge with another individual ' $B$ ' who at 17 years of age with no prior kitchen experience/training whatsoever, who has now accomplished a (formal) chef/ culinary diploma training of, let's say approximately 4 years, now competent to serve in a restaurant. Undoubtedly, if at these two individual scenarios, both are to function efficiently with FHMS concepts/principles, a clean kitchen environment must be sustained, all of which directly determines the degree of high quality safety of food raw material, preparation and consumption stages. Given these (abovementioned) contexts, we hereby propose a scheme that shows the human activity/participation during food (as) raw material, preparation, and consumption stages adding food contamination that can progress onto poisoning, all within the kitchen environment, as showed in Fig. 1. And notwithstanding that food contamination can take place at any stage(s) of food raw material, preparation, and consumption process, all of which are considered within the kitchen environment, improper / unsafe handling of raw food materials, would most likely from the very onset, increase the probability of (food) contamination and in the worst case scenario, poisoning, can subsequently take place.

A scenario that do occur across various homes can be considered here, for example, where used kitchen utensils e.g., plates, spoons, forks, etc., after dinner remain overnight in sink unwashed until next (day) morning. Not only is it a very bad household kitchen (hygiene) habit/practice, such leftover food particles can create an avenue for some (of its earlier stages of) microbial decomposition processes to start, which when it advances would result in foul odour that spoils the atmosphere of kitchen

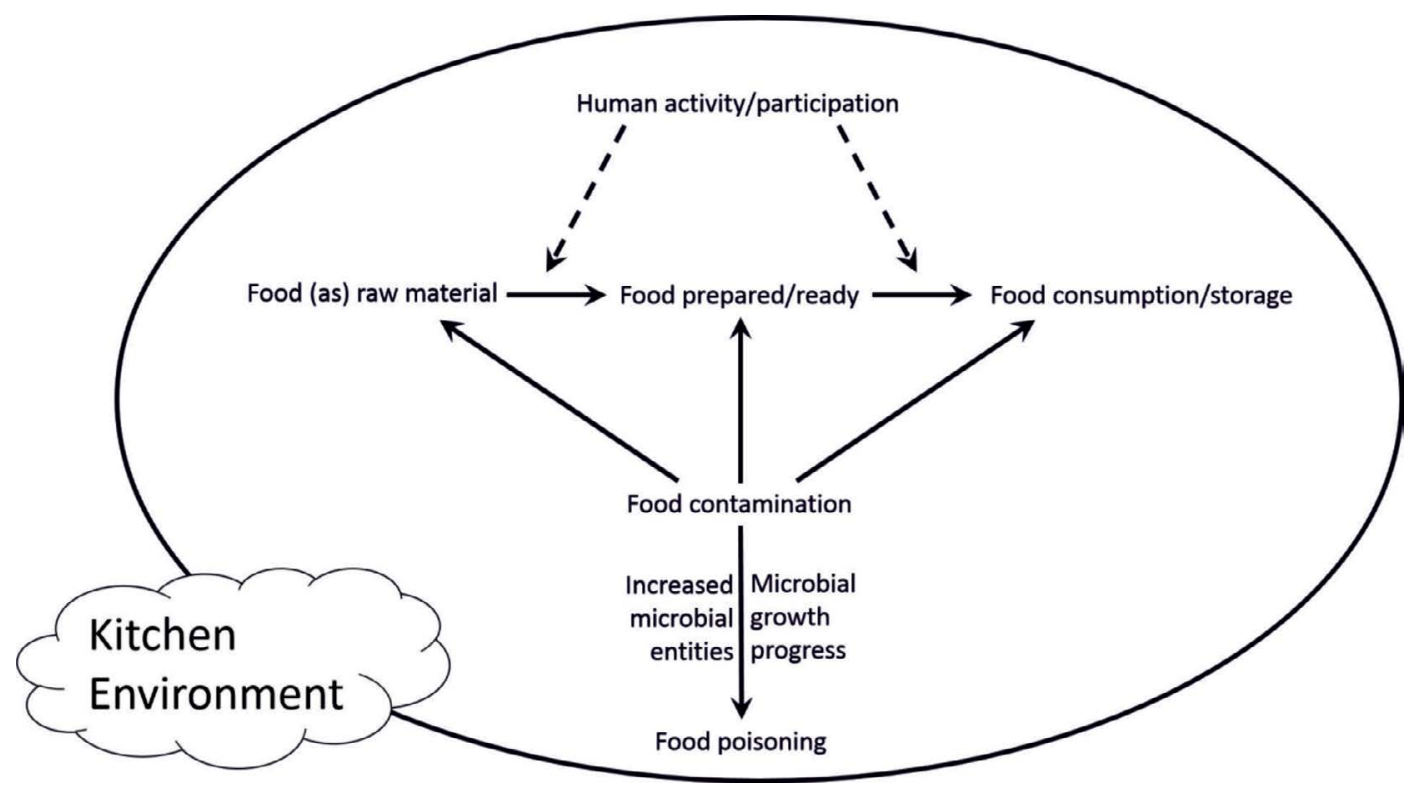

Fig. 1. Human activity/participation during food (as) raw material, preparation, and consumption/stages adding food contamination that can progress onto poisoning, all within the kitchen environment. 
environs. Such unwashed used utensils (left in sink) can promote food contamination especially if nearby, there is unfinished food dish (in a pot and on the cooker) to be consumed the very next day (morning). Considering that cooker and sink may likely be near to each other as found in many small-like household kitchens, food contamination can take place, which may well bring about food poisoning. The start of such scenario can be when a kitchen user, in the process of washing such used utensils (if done by hand and little-to-no caution applied), may allow (without any knowledge of its occurrence) little bits of decomposing food particles finding its way between sink and cooking pot surface(s). And from that, through kitchen user's poor handling of leftover food pot, can possibly make the microbial entity on the pot surface gain entry into the food, to bring about either possible contamination and/or even poisoning in a worst case scenario. Clearly, literature has also reiterated that poor hygiene and improper food handling do pose a significant risk of food contamination as well as poisoning. Importantly, persons who handle food (food handlers) are very vital in ensuring food safety as well as preventing disease/illness situations because both poor hygiene and ineffective hand washing remain among significant risk factors of food contamination that result in food poisoning ${ }^{42}$.

Thus, the food hygiene practices which consumers adopt especially while cleaning, cooking, preparation, serving and storage of food are very key in determining the root cause of large number of foodborne diseases/illnesses ${ }^{34}$. Human participation pathway to utilize food hygiene/ microbiological safety (FHMS) concepts/ principles in domestic/ household kitchen is depicted in Figure 2. Essentially, kitchen users should get equipped with (some) knowledge base of FHMS concepts/principles in the view to achieve its effective and efficient application onto domestic/household kitchen components. Acquiring such knowledge base should therefore be considered a pre-requisite step before such FHMS concepts/principles can be constructively, effectively and successfully utilized and sustained within the domestic/household kitchen context(s) and (extended) beyond. Indeed, consumers have a key role to play in the prevention of foodborne disease incidence. Although it is generally believed that consumers do have some awareness about appropriate steps that can prevent spread of foodborne illness/disease especially from the point of preparing up to handling of food, many yet do not put that knowledge and understanding into practice ${ }^{34}$.

A summary of some do's and don'ts of food hygiene/microbiological safety (FHMS) applicable to domestic/household kitchen is presented in Table 2. Whilst this is not an exhaustive tabulation, it is clear that there is more do's compared with don'ts. If a parent had either changed dippers or used the washroom or taking out the garbage, it is important to wash hands before and after. If gloves are worn, there should be caution because it can catch fire. Generally, cleanliness of kitchen needs to be sustained and can be achieved by observing key basic routines, for example, disposing food scraps properly and removing crumbs, wiping table tops clean with soap, sweeping and wet mopping floors, cleaning all surfaces including handles and knobs, refrigerator handles, ovens, etc. Dishcloths, aprons and towels should be laundered regularly using washing machine. Besides, cutting boards (whether it is either plastic or wood) for example should be cleaned, disinfected after use and allowed to dry properly prior to (any) re-use. Also, can openers, for example, should be cleaned thoroughly immediately after (each) use. Importantly, frozen food must be thawed either in refrigerator, microwave and oven, or by placing sealed packages in cold running water. Importantly also, all kitchen users must adhere to instructions stated, for example, on grocery packs, etc., and place those food items that require either refrigeration and/or freezing as soon as possible after purchase respectively in either refrigerator or freezer ${ }^{43}$. In addition, the essence of storing food in airtight containers is to ensure limited to zero aeration, and importantly, limited to zero exposure to any form of microbial elements. Essentially, whilst all spills should get cleaned immediately to avoid slipping and other (kitchen) accidents, it will largely minimize the incidence and spread of food pathogens ${ }^{44}$.

Home kitchens are well known to serve, not only as storage place(s), but also as multipurpose areas. Kitchen sinks serve the purpose of dishwashing, soaking clothing, washing children, and wetting mops. Whilst food safety 
chain has the home as the 'last line of defense', it is believed by many that food handling errors are most likely committed by men, either adults younger than 30 years or older than 64 years, and those with at least some post-secondary education ${ }^{45}$. According to ServSafe ${ }^{\circledR}$ for instance, if cleaning and sanitizing are to become very effective, it must follow a four-step process. That is to say that surfaces must be cleaned, rinsed, sanitized, and allowed to air dry ${ }^{12}$. And because most foodborne illnesses appear sporadic, mild, unconfirmed and unreported, researchers believe

Table 2: Basic/fundamental do's and don'ts of food hygiene/ microbiological safety (FHMS) applicable to domestic/ household kitchen
Do's
Dont's

1) Wash hands before and after handling raw food;

2) Cover any cuts with bandage and wear clean gloves;

3) Wear hair nets to help prevent loose hair from falling on food;

4) Use utensils to serve food whenever possible;

5) Use clean spoon each time to sample/taste food;

6) Inspect kitchen for signs of microbiological growth;

7) Inspect kitchen for any plumbing leaks;

8) Use effective cleaning agents/ disinfectants;

9) Make sure cleaning materials are nearby;

10) Clean food storage area regularly especially for dry food types;

11) Always use separate cutting boards for raw meat;

12) Wash, rinse, sanitize and dry cutting boards/utensils before re-using;

13) Wash lids of canned foods before opening to keep dirt from getting into the contents;

14) Store (wet) food packages on plates to prevent its drip on kitchen work top surfaces or other food;

15) Keep cooked food warmer than $60^{\circ} \mathrm{C}\left(140^{\circ} \mathrm{F}\right)$ or cooler than $4^{\circ} \mathrm{C}\left(40^{\circ} \mathrm{F}\right)$;

16) Keep refrigerator set at $4^{\circ} \mathrm{C}\left(40^{\circ} \mathrm{F}\right)$;

17) Keep frozen food at $-18^{\circ} \mathrm{C}\left(0^{\circ} \mathrm{F}\right)$ or less;

18) Remove garbage regularly and properly;

19) Keep garbage tightly covered;

20) Food should be stored in airtight containers; and

21) Use microwave approved containers

Adapted from these sources:[Refer to Reference 43] https://www.ccohs.ca/oshanswers/prevention/kitchen_hygiene.html; Accessed 17 April 2019, 23.28 h GMT; [Refer to Reference 44] https://guardian.ng/features/28-tips-for-food-hygieneandkitchensafety/; Accessed 17 April 2019, $21.01 \mathrm{~h}$ GMT. 


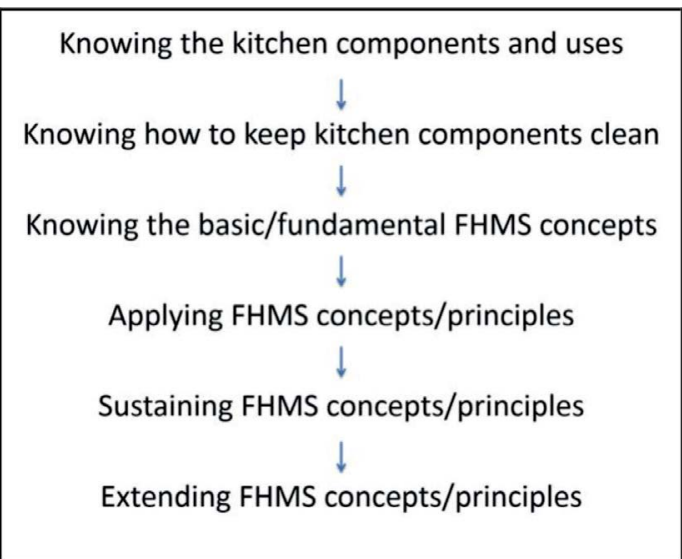

Fig. 2. Human participation pathway to utilize food hygiene microbiological safety (FHMS) concepts/ principles in domestic/ household kitchen.

that the cases originating from food handling errors at home could be much higher although many consumers still do not consider the home a place of risk for foodborne illnesses ${ }^{45}$. Certainly, poor food hygiene practices would progress the incidence of foodborne diseases, which makes the implementation of food hygiene training very essential ${ }^{46}$. Besides, it is believed that the most food hygiene training courses may well show to rely heavily on the provision of (useful) information. If food hygiene training were to be made effective, it needs to target (some) change(s) in those behaviors that would most likely result in food-borne illness ${ }^{47}$.

\section{CONCLUSION}

A concise review on basics the general public needs to know about food hygiene/ microbiological safety (FHMS) in household kitchens has been performed. There is documented evidence that the kitchen contributes significantly to the incidence and spread of foodborne illnesses and the general public must recognize this fact. With the increasing incidence of foodborne illnesses reported globally, the typical household kitchen, as the last 'line of defense' for consumers, remains among places that require high-level quality practice of food hygiene and microbiological safety. Notwithstanding the factors that bring about food spoilage, how foodborne pathogens are able to either survive and/or thrive on a given food (dish) prepared within the household kitchen should never be underestimated. Therefore, a clean and healthy kitchen is very essential to sustain high quality level of food hygiene microbiological safety. On the other hand, the incidence of microorganisms across kitchen components is largely caused by factors ranging from cross-contamination, wetness of kitchen surface up to resident microbial flora. Given that the 'infectious dose' of many common foodborne pathogens is always very small makes the effectiveness of hand hygiene very important. Because microbial reservoirs can build-up, the application of routine disinfection/sanitization of household kitchen is very essential. Even if food handling errors do arise, the continuous as well as holistic observation of these (abovementioned) do's and don'ts that helps to assure the optimization of FHMS conditions in a typical household kitchen would actually go a long way to help prevent the incidence of foodborne diseases/ illnesses.

\section{ACKNOWLEDGEMENTS}

Authors thank Engr. Adetunji Alabi (Masdar Institute-Khalifa University UAE) for his help in the figures. Importantly, authors did not receive any funding to conduct this review.

\section{CONFLICT OF INTEREST}

Authors declare that there is no conflict of interest associated with this review study.

\section{AUTHORS' CONTRIBUTION}

All authors have made substantial, direct and intellectual contribution to the work and approved it for publication.

\section{FUNDING}

None.

\section{DATA AVAILABILITY}

All datasets generated or analyzed during this study are included in the manuscript and/or the Supplementary Files.

\section{ETHICS STATEMENT}

This article does not contain any studies with human participants or animals performed by any of the authors. 


\section{REFERENCES}

1. Gorman, R., Bloomfield, S., Adley, C.C. A study of cross-contamination of food-borne pathogens in the domestic kitchen in the Republic of Ireland. Int. J. Food Microbiol. 2002; 76 (1-2): 143-150.

2. Foodborne Outbreaks: In: Centers for Disease Control and Prevention; https://www.cdc.gov/foodsafety/ outbreaks/index.html; Accessed 17 April 2019, 20.41 h GMT.

3. Røssvoll, E., Langsrud, S., Bloomfield, S., Moen, B., Heir, E., Møretrø, T. The effects of different hygiene procedures in reducing bacterial contamination in a model domestic kitchen. J. Appl. Microbiol. 2015; 119: 582-593.

4. Be Smart. Keep Foods Apart. Don't Cross Contaminate; https://www.fsis.usda.gov/wps/portal/fsis/topics/ food-safety-education/get-answers/food-safety-factsheets/safe-food-handling/be-smart-keep-foodsapart/CT_Index, Accessed 17 April 2019, 09.11 h GMT.

5. Lund, B.M. Microbiological Food Safety for Vulnerable People. Int. J. Environ. Res. Public Health 2015; 12(8): 10117-10132.

6. Food Safety: In World Health Organization; https:// www.who.int/foodsafety/areas_work/food-hygiene/ en/; Accessed 17 April 2019, 09.33 h GMT.

7. What is Food Safety? In Australian Institute of Food Safety; https://www.foodsafety.com.au/resources/ articles/what-is-food-safety; Accessed 17 April 2019, $09.27 \mathrm{~h} \mathrm{GMT}$.

8. Food Poisoning - Prevention: In Better Health Channel of Victoria State Government of Australia; https:// www.betterhealth.vic.gov.au/health/healthyliving/ food-poisoning-prevention; Accessed 17 April 2019, $09.31 \mathrm{~h} \mathrm{GMT}$

9. Foodborne Diseases: In World Health Organization; https://www.who.int/topics/foodborne_diseases/en/; Accessed 17 April 2019, 09.34 h GMT

10. Foodborne Illnesses: In National Institute of Diabetes and Digestive and Kidney Diseases; https://www. niddk.nih.gov/health-information/digestive-diseases/ foodborne-illnesses; Accessed 17 April 2019, 09.37 h GMT.

11. Oral Health: Centers for Disease Control and Prevention; In https://www.cdc.gov/oralhealth/ infectioncontrol/glossary.htm; Accessed 17 April 2019, 10.08 h GMT.

12. Cleaning Vs Sanitizing; In ServSafe ${ }^{\circledR}$ https://www. servsafe.com/ServSafe/media/ServSafe/Documents/ poster_11.pdf; Accessed 17 April 2019, 09.47 h GMT.

13. Microbial Growth (Power Point Presentation \{Anonymous\}); https://www.lamission.edu/ lifesciences/lecturenote/mic20/Chap06Growth.pdf; Accessed 17 April 2019, $09.51 \mathrm{~h}$ GMT.

14. Venter, P., Shale, K., Lues, J.F.R., Buys, E.M. Microbial proliferation and mathematical indices of vacuumpacked bovine meat. Journal of Food Processing and Preservation 2006; 30(4): 433-448.

15. Food or water borne illnesses: In health.vic (Victoria Hub for Health Services and Business) of Victoria State Government of Australia; https://www2. health.vic.gov.au/public-health/infectious-diseases/ disease-information-advice/food-water-borne-illness;
Accessed on 17 April 2019, 20.47 h GMT.

16. Normal bacterial Flora on hands - In WHO Guidelines on Hand Hygiene in Health Care: First Global Patient Safety Challenge Clean Care Is Safer Care; https:// www.ncbi.nlm.nih.gov/books/NBK144001/; Accessed 17 April 2019, $10.12 \mathrm{~h}$ GMT.

17. Davey, M.E., O'toole, G.A. Microbial Biofilms: from Ecology to Molecular Genetics. Microbiol. Molecular Biol. Rev. 2001; 64(4): 847-867.

18. Signs and Symptoms; In Nature: http: //www.nature. com/subjects/signs-and-symptoms; Accessed on 04 June 2019, 14.10 h GMT.

19. Nall, R. Everything You Should Know About Nausea. In HealthLine, Medically reviewed by Saurabh Sethi on April 30, 2019, (http: //www.healthline.com/health/ nausea; Accessed 04 June 2019, 14.15 h GMT).

20. Whitlock, J. Bacteremia - Causes and Diagnosis. In: Verywellhealth, Updated May 12, 2019 (http://www. verywellhealth.com/bacteremia-defined-3157048, Accessed 04 June 2019, 14.19 h GMT).

21. Torrey, T. Difference Between Sepsis and Septicemia - One is the cause and the other is the effect. In Verywellhealth, Updated in December 07, 2018, (http://www.verywellhealth.com/sepsis_and_ septicemia-2615130; Accessed 04 June 2019, 15.22 h GMT).

22. McGill, M. What you should know about diarrhea. In MedicalNewsToday; Last Updated 28 November 2017 (https://www.medicalnewstoday.com/ articles/158634.php, Accessed 19 June 2019, 09.40 h GMT).

23. Blake, K. What Causes Hemorrhage? In: Healthline (http://www.healthline.com/symptom/hemorrhage, Reviewed medically on October 28, 2016; Accessed 11 June 2019, 12.40 h GMT).

24. Pathogenicity vs Virulence - http://www.tulane. edu/ wiser/protozoology/notes/pth.html; Accessed 07 June 2019, 00.24 h GMT

25. Heredia, N., Garcia, S. Animals as sources of food-borne pathogens: A review. Animal Nutr. 2018; 4(3): 250-255.

26. Chlebicz, A., lizewska, K. Campylobacteriosis, Salmonellosis, Yersiniosis, and Listeriosis as Zoonotic Foodborne Diseases: A Review. Int. J. Environ. Res. Public Health, 2018; 15, 863; doi: 10.3390/ ijerph15050863.

27. Dhama, K., Rajagunalan, S., Chakraborty, S., Verma, A.K., Kumar, A., Tiwari, R., Kapoor, S. Food-borne Pathogens of Animal Origin - Diagnosis, Prevention, Control and Their Zoonotic Significance: A Review. Pak. J. Biol. Sci. 2013; 16(20): 1076-1085

28. Sharma, M., Eastridge, J., Mudd, C. Effective household disinfection methods of kitchen sponges. Food Control 2009; 20:310-313.

29. Teixeira, P., Lima, J., Azeredo, J., Oliveira, R. Adhesion of Listeria monocytogenes to materials commonly found in domestic kitchens. Int. J. Food Sci. Technol. 2008; 43: 1239-1244.

30. Oliveira, K., Oliveira, T., Teixeira, P., Azeredo, J., Henriques, M., and Oliveira, R. Comparison of the Adhesion Ability of Different Salmonella Enteritidis Serotypes to Materials Used in Kitchens. J. Food Protect. 2006; 69 (10), 2352-2356. 
31. Nwachukwu, I.M., Nwachukwu, I.O. 2014. Modern Food Microbiology, pp. 198, Owerri, Nigeria: Milestone Publishers Ltd., (ISBN: 978-978-52644-5-6).

32. Tachi, J., Carpentier, B. Hygiene in the home kitchen: changes in behavior and impact of key microbiological hazard control measures. Food Control 2014; 35: 392 400.

33. Grasso, L., Silverberg, R., Baker, G.L., GoodrichSchneider, R.M., Schneider, K.R. Food safety within the household: risk reduction. FSHN 12-10. Food Science and Human Nutrition Department, UF/IFAS Extension, http://edis.ifas.ufl.edu/. Accessed April 12, 2019.

34. Vyas, S., Kushwaha, A. Consumer's perception and knowledge concerning safety of street food services in Pantnagar, India. J. Food Safety Hygiene 2017; 3(1-2): 34-39.

35. Food Safety and Hygiene - The 4 Cs: In Dettol's Healthy Kitchen and Dining; https://www.dettol.com.au/ healthy-homes/healthy-kitchen-and-dining/foodsafety-and-hygiene/, Accessed 17 April 2019, $20.56 \mathrm{~h}$ GMT.

36. Redmond, E.C., Griffith, C.J. Consumer Food Handling in the Home: A Review of Food Safety Studies. J. Food Protect. 2003; 66(1): 130-161.

37. Bloomfield, S., Exner, M., Fara, G.M., Nath, K.J., Scott, E.A. Hygiene procedures in the home and their effectiveness: A review of the scientific evidence base. Scientific Advisory Board of Internet Science Forum on Home Hygiene (www.ifh_homehygiene.org).

38. Rossi, E.M., Scapin, D., Grando, W.F., Tondo, E.C. Microbiological Contamination and Disinfection Procedures of Kitchen Sponges Used in Food Services. Food Nutr. Sci. 2012; 3, 975-980.

39. Saad, M., See, T.P., Adil, M.A.M. Hygiene Practices of Food Handlers at Malaysian Government Institutions
Training Centers. Procedia Soc. Behavioural Sci. 2013; 85: 118-127.

40. Sinclair, R.G., Gerba, C.P. Microbial contamination in kitchens and bathrooms of rural Cambodian village households. Letters Appl. Microbiol. 2010; 52: 144-149.

41. Alegbeleye, O.O., Singleton, I., Sant'Ana, A.S. Sources and contamination routes of microbial pathogens to fresh produce during field cultivation: A review. Food Microbiol. 2018; 73: 177-208.

42. Lee, H.K., Halim, H.A., Thong, K.L., Chai, L.C. Assessment of Food Safety Knowledge, Attitude, SelfReported Practices, and Microbiological Hand Hygiene of Food Handlers. Int. J. Environ. Res. Public Health 2017; 14, 55 (https://doi:10.3390/ijerph14010055).

43. Food and Kitchen Hygiene: In Prevention and Control Hazards of OSH Answers- Canadian Centre for Occupational Health and Safety; https://www.ccohs. $\mathrm{ca} /$ oshanswers/prevention/kitchen hygiene.html; Accessed 17 April 2019, 23.28 h GMT.

44. Odusanya, Y. 28 tips for food hygiene and kitchen safety: In Food and Drink - The Guardian (Features) reported in 18 November 2017 (4.16 am); https:// guardian.ng/features/28-tips-for-food-hygiene-andkitchen-safety/; Accessed 17 April 2019, 21.01 h GMT.

45. Byrd-Bredbenner, C., Berning, J., Martin-Biggers, J. Quick, V. Food Safety in Home Kitchens: A Synthesis of the Literature. Int. J. Environ. Res. Public Health 2013; 10: 4060-4085.

46. Lestantyo, D., Husodo, A.H., Iravati, S., Shaluhiyah, Z. Safe Food Handling Knowledge, Attitude and Practice of Food Handlers in Hospital Kitchen. Int. J. Public Health Sci. 2017; 6(4): 324-330.

47. Egan, M.B., Raats, M.M., Grubb, S.M., Eves, A., Lumbers, M.L., Dean, M.S., Adams, M.R. A review of food safety and food hygiene training studies in the commercial sector. Food Control 2007; 18: 1180-1190. 